\title{
Revenue Management In Manufacturing: A Research Landscape
}

S. Hossein Cheraghi, Western New England College, USA

Mohammad Dadashzadeh, Oakland University, USA

Prakash Venkitachalam, Wichita State University, USA

\begin{abstract}
Revenue management is the science of using past history and current levels of order activity to forecast demand as accurately as possible in order to set and update pricing and product availability decisions across various sales channels to maximize profitability. In much the same way that revenue management has transformed the airline industry in selling tickets for the same flight at markedly different rates based upon product restrictions, time to departure, and the number of unsold seats, many manufacturing companies have started exploring innovative revenue management strategies in an effort to improve their operations and profitability. These strategies employ sophisticated demand forecasting and optimization models that are based on research from many areas, including management science and economics, and that can take advantage of the vast amount of data available through customer relationship management systems in order to calibrate the models. In this paper, we present an overview of revenue management systems and provide an extensive survey of published research along a landscape delineated by three fundamental dimensions of capacity management, pricing, and market segmentation.
\end{abstract}

Keywords: Revenue Management, Yield management, Supply Chain Management, Capacity Planning, Dynamic Pricing, Market Segmentation

\section{INTRODUCTION AND BACKGROUND}

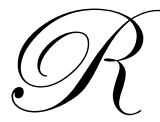

evenue management, as a science, has its origins in the airline industry. Early 70's saw some of the airlines offering discounted fare. This was a practice adopted by the airlines to obtain additional revenue from the seats which would otherwise fly empty. This practice brought forth the problem of determining the number of seats which should be protected for late full fare booking requests. If more than enough seats were protected for future full fare booking, then the flight would depart with empty seats. On the other hand, if sufficient seats were not protected, then the airline would lose a full fare customer, which is tantamount to losing the opportunity to make additional revenues. It quickly became clear that development of effective control of the number of discount seats to be offered required some kind of tracking of booking histories, enhanced information system capabilities, and careful research and development of seat inventory control decision rules. Littlewood (1972) of British Airways proposed that as long as the revenue value exceeded the expected revenue of future full fare booking, discount fare bookings should be accepted. This proposal marked the beginning of the science of revenue management.

A revenue management system encompasses creative methods and practices to improve operations and ultimately the bottom line. It is about "selling the right product to the right customer at the right price at the right time" (Talluri and van Ryzin, 2004). Revenue management deals with maximizing revenue for a fixed capacity of a product or service. It saves the capacity for the most valuable customer by proper capacity allocation and constantly attempts to understand, anticipate, and then react to consumer behavior in order to maximize revenue/profit.

As the initial myopia of seeing the principles only in airline specific terms gave way, from the early 90 's, researchers began looking at the applications of revenue management principles to the field of manufacturing. In a 
manufacturing setting, revenue management principles help balance demand and supply more effectively by addressing all three categories of demand management decisions - structural, pricing, and quantity decisions. Structural decisions deal with segmentation of the market, bundling of products, and terms of trade, including volume discounts, cancellations, and refund options. Pricing decisions deal with pricing over product categories and time-varying pricing in addition to discounts offered over products' lifetimes. Quantity decisions address whether or not to accept an offer to buy, and how much capacity to allocate to different segments, products, or sale channels. As pointed out by Talluri and van Ryzin (2004), although these fundamental demand management decisions have always challenged sellers, what is new about revenue management today is that the advances in decision modeling, combined with information technology to capture and process vast amount of data, have created a unique opportunity for sellers to move their decision-making toward the optimum.

In this paper, we present an overview of revenue management systems and provide an extensive survey of published research along a landscape delineated by the three fundamental dimensions of capacity management, pricing, and market segmentation.

\section{REVENUE MANAGEMENT IN MANUFACTURING}

Revenue management decision models dealing with empty seats (unfulfilled capacity) in the airline industry hinted at considerable potential of such innovative ideas for manufacturing. A similar situation occurs in manufacturing when unfulfilled capacity causes increased cost of production since orders accumulate in peak load periods resulting in higher cost/price of the product and potential loss of the market share. Compounding the problem is that most manufacturing firms have demand variability, customer heterogeneity, and some kind of supply or production inflexibility.

To adapt the principles of revenue management established for airline industry to manufacturing, it is important to identify the similarities and differences between the two industries. In both, demand is stochastic and capacity is perishable, limited, and cannot be easily changed (Modarres and Nazemi, 2005). However, manufacturing is increasingly becoming customized and flexible in order to meet customers' specific expectations regarding product specifications. This implies that manufacturing companies are more and more selling their capacity and manufacturability to the customers, thereby adding subtle dimensions to the revenue management decision models.

\subsection{Capacity Management}

Make to order (MTO) companies meet their demand by hedging against their capacity while make to stock (MTS) firms meet their demand by holding inventory on hand. As such, the most critical problem MTO firms face is to utilize their capacity in the most optimum fashion to satisfy the demand in the system. In this context, the most important thing to keep in mind is that unused capacity is similar to lost revenue opportunity in airlines. When we take the case of companies having multiple product classes, the allocation of capacity is similar to the order acceptance or refusal decision in revenue management. The acceptance or refusal is based on maximizing the profit potential of the scarce capacity by accepting only the most profitable order.

\subsection{Market Segmentation}

In a general market for products customers can be segmented into different groups based on their willingness to pay different prices for the same product. One class of customers wants to pay less but is willing to wait longer and thus is tolerant of longer lead times. Another class needs shorter lead times and better service and is willing to pay more for that. This presents a revenue management opportunity by introducing some kind of segmentation or differentiation mechanism. The various possibilities for market segmentation include varying lead times (shorter lead times at higher price), variation in after sales warranty, different cancellation policies for different classes of customers, and generally higher flexibility allowed for higher priced segments (Modarres and Nazemi, 2005). 


\subsection{Pricing in Manufacturing}

Pricing has been the most obvious tactic to balance the sales revenue stream of a firm. It helps in optimizing the revenue by introduction of higher prices when demand is strong and keeps the business afloat by lowering the price when sales are not good. However, pricing also plays an important role vis-à-vis the key concept in revenue management, i.e., capacity perishability. In the case of airlines capacity perishability refers, of course, to an empty seat after the flight departs reflecting the lost revenue opportunity. But, in the case of manufacturing the capacity utilized to build products that can be stored and later sold is, at first glance, not seen as perishable. However, the prevalence of high competition in industry is forcing the perspective to view manufacturing capacity as perishable. For example, even though cars can be produced and stored in completed inventory, if we are not able to sell our car in a competitive market and our competitor achieves the sale, then this is increasingly viewed as a lost revenue making opportunity.

Airlines offer a large number of fares for the same market of customers and charging different fares for the same seat. This is achieved by some kind of structural variation in terms of sale such as 30 day advance reservation to give discounts. The same situation applies in manufacturing where price sensitive customers will be willing to allow a reasonable period of time before the date of delivery of the final product. Therefore, as in the airline industry, it is possible to develop decision models for manufacturers that help segment the market in order to maximize revenue based on controlling price or quantity. To that end, in the next section we present a comprehensive survey of revenue management literature relevant to manufacturing.

\section{A RESEARCH LANDSCAPE OF REVENUE MANAGEMENT IN MANUFACTURING}

There have been previous literature surveys of revenue management research. Weatherford and Bodily (1992) provide a general categorization of perishable asset management problems. They classified the published work and introduced a general taxonomy for the revenue management literature. The term "Perishable Asset Revenue Management (PARM)" for the general class of inventory control problems is introduced into the literature by their research.

The general revenue management literature is also discussed in (McGill and van Ryzin, 1999) where a comprehensive survey of revenue management literature in airline industry may be found. They review the models developed under the research classification of forecasting, overbooking, inventory control, and pricing problems. Pak and Piersma (2002) and Bitran and Caldentey (2003) also give a review of operations research techniques for airline revenue management problems. The latter review emphasizes pricing research related to revenue management and presents main results, practical implications, and insights into future research opportunities.

Elmaghraby and Keskinocak (2003) review the literature on dynamic pricing in presence of inventory considerations. They point out that there has been an increasing interest in the adoption of dynamic pricing in industry for several reasons including increased availability of demand data, easy implementation of price changes due to new technologies, and the development of decision support tools for analyzing demand data and pricing.

In make to stock (MTS) manufacturing environment, several researchers have addressed the problem of allocating scarce inventory among competing classes of customers. Cohen (1977) presents one of the earliest works in this direction. In service operations management, the subject has been studied by a variety of researchers including Kimes (1989) for airlines, in the hotel industry by Relihan (1989), and in car rental industry by Carrol and Grimes (1995). These researchers focus on the objective of allocating scarce resources to the most valuable customer.

\subsection{Pricing Research}

Pricing is the most researched area in manufacturing revenue management. And, not surprisingly, most of the published research in pricing has focused on make to order (MTO) systems since pricing principles are more applicable in these manufacturing environments. 


\subsubsection{Pricing in Make To Stock (MTS) Manufacturing}

Gayon et al. (2009) present the potential benefits of dynamic pricing in a controlled production environment where demand is fluctuating but dependent upon the price offered at the time of transaction. Extending this research Gayon and Dallery (2007) studied the impact of pricing on a partially controlled production environment and showed that the impact of dynamic pricing in generating better profits over static pricing is more pronounced in such a production environment.

Caldentey and Wein (2006) considered an electronic market with two selling channels, namely long term contracts and spot market. The manufacturer's problem is to accept or reject incoming orders to maximize revenue while reducing inventory, holding, and backorder costs. In the study they have shown that segregating orders and accepting the high priced ones by the proposed order acceptance policy helped the system achieve higher profits than the random acceptance of incoming orders.

Another line of research considers the impact of competition in the decision model. Adida and Perakis $(2006,2009)$ considered a multi product capacitated dynamic setting where demand is a linear function of the price of the supplier and the firm's competitors and present an optimization approach to incorporate demand uncertainty in a dynamic pricing environment.

\subsubsection{Pricing in Make To Order (MTO) Manufacturing}

To our knowledge, the first work on pricing related to manufacturing revenue management is Gallego and van Ryzin (1993). They developed the upper bound of revenues in a model where demand is price sensitive and stochastic and the firms have the sole objective of maximizing revenues. Feng and Xiao (2000) investigated a similar situation with a continuous time yield management model and obtained the exact solution compared to the deterministic heuristic offered in previous research.

Morris (2001) developed a simulation based model for implementation of dynamic pricing strategies in real life markets. Swann (2001) investigated pricing strategies to improve the supply chain performance in a system where pricing and production decisions are taken in a multi period horizon. The results of the study show that dynamic pricing can be used as a significant tool to absorb demand variability in supply chains and significant profits can be attained by a few price changes. Indeed, the results of the study posit that price changes can be as high as $10 \%$ of the fixed price.

Montgomery (2004) presented a pricing decision support system which takes into account demand and variation in demand due to consumer response to price changes. Jayaraman and Baker (2003) investigated the impact of Internet as an enabler for instantaneous/dynamic pricing. The study explored the possibilities offered for revenue management by auctions, reverse auctions, exchanges, and negotiations.

Maglaras and Zeevi (2004) designed an innovative model of a service system with two different types of service: a guaranteed $(\mathrm{G})$ class and a best effort (B) class. In this model, the customers are sensitive to both price and congestion occurring in the system. Design variables are such that the residual capacity not used by $\mathrm{G}$ class is allocated to B class and there will be a mechanism which informs the consumers about the state of congestion in the system. For the proposed system, an "almost" optimal pricing rule for the two classes of service is derived. Furthermore, it is shown that notifying customers of real time congestion effects has increased the revenue.

$\mathrm{Xu}$ and Hopp (2005) studied the significance of the learning process in predicting demand for inventory and the corresponding pricing rules. Netessine (2006) considered the costs associated with varying prices and proposed a piecewise constant pricing policy to limit price adjustments. The study showed that timing of price changes and proper capacity allocation are critical for optimal profits.

Aggarwal et al. (2004) proposed using consumer profiles and purchasing patterns available due to advances in customer relationship management for increasing revenue. The study proposes to strategically set prices to different products after taking into account the customer's choices. Fleischmann et al. (2004) investigated the 
relation between pricing and manufacturing operations. Biller and Swann (2006) also considered pricing decisions influencing the operations of a firm. A similar research in the operations direction was conducted by Celik and Maglaras (2008) and they propose the combined use of pricing and lead time quotations to optimize long term revenue and profits of the firm.

Narahari et al. (2005) surveyed different models used in dynamic pricing and discussed the situations under which each model is likely to succeed. Araman and Caldentey (2009) introduced the learning factor in the setting of dynamic pricing. Bitran and Caldentey (2003) studied the impact of consumer behavior on demand and pricing. Their model proposes an optimal pricing policy after considering the consumers' purchasing behavior for a particular price.

Shen and Su (2007) have considered pricing with the view point of strategic consumer behavior. The study considered a system where the monopolist sells inventory over a finite time horizon. In this model the seller varies the price as the customers come in to the system in a continuous manner. At each point, customers can exercise three different options: to buy the product at the current price, to exit, or to stay in the market to buy later. Each and every customer has different valuations for the product at the same point of time and different degree of patience. The study proposes different strategies for different customers.

Another interesting line of research in pricing is the joint consideration of pricing and inventory to determine the optimal levels of pricing and inventory in order to maximize profits. Aydin and Porteus (2005) conducted an investigation of a system where the model of demand involves multiplicative uncertainty. They showed that as competition increases the price of the product goes down, and as quality of product improves the price also increases. The study claims that the model gives the optimal prices under a given inventory condition.

Lin (2006) studied the impact of learning in dynamic pricing. This research focused on the specific problem when the firm does not possess accurate demand forecasts. Rather, it uses real time sales data to calculate the arrival rate information. The author points out that for most industries, real time demand data can be a more accurate estimate of future forecast than using historical demand data.

\subsection{Capacity Planning Research}

From revenue management perspective, effective use of a manufacturing facility at optimum levels involves key decisions such as how best to use the available capacity and whether the capacity available should be set aside for the prospect of a more valuable customer. In this section, we survey capacity planning research in manufacturing revenue management under the classification of order selection and capacity allocation decision problems.

\subsubsection{Order Selection}

Order selection decision involves accepting or rejecting an offer to buy the product or capacity in a manufacturing environment. The objective is to accept those orders which will maximize revenue and profitability. In other words, order selection decision rules attempt to serve higher end customers and only accept lower end customers if manufacturing capacity remains unused.

To the best of our knowledge, Carr and Duenyas (2000) presented the first research examination of the order acceptance/rejection decision problem. They characterized the problem as a sequencing and admission control problem in a production system with two classes of products: a make to stock product that the firm is committed to deliver and a make to order product that the firm is free to accept or reject the order offer. They derive a policy of how to make the decision in a single server queue environment. A similar problem was investigated by Kuhn and Defregger (2007). They considered a make to order manufacturing company which receives orders of different processing times, due dates, and profit margins. They develop a heuristic for acceptance/rejection using a Markov decision model. 
Charnsirisakskul et al. (2004) investigated the problem of order selection when the manufacturer has the flexibility to choose his lead time. The focus of the research is to arrive at a mechanism to coordinate lead time and order selection and to find out under what flexible arrangements for lead time the manufacturer can attain maximum profit levels. Gallien et al. (2004) discuss a framework for negotiating lead time, price, and quantity. They use the concept of minimum workload function to establish that early due date scheduling can be assumed with no cost to optimality. They derived two heuristic policies and showed with computational results that the proposed formulation is superior to early due date scheduling for profitability.

Kuhn and Defregger (2007) investigated the order selection problem from the perspective of inventory capacity. Their research shows that considering the problem as revenue management yields better results than the traditional First Come First Served policy.

Another interesting research direction in order selection is when the firm prioritizes orders and implements the order selection procedure into its production scheduling. Geunes et al. (2006) developed a planning model that integrates pricing and production planning to obtain optimal revenues and profits for the manufacturing facility.

\subsubsection{Capacity Allocation}

The most important resource of a manufacturing firm is capacity and the fundamental capacity allocation principle for revenue management involves allocating the available capacity to the most valuable customer. Harris and Pinder (1995) were first to investigate this decision problem. They considered an assemble to order environment and proposed pricing strategies and stop sales tactics to optimally allocate the pre-existing capacity. An important contribution of this work is the theoretical framework it provided for future research.

Kapuscinski and Tayur (2000) studied a basic discrete time model of capacity reservation in a make to order environment for two different classes of customers with a stochastic demand. Feng and Xiao (2000) investigated the case where finite products are sold to two different markets at their respective prices. To manage revenues, at times management must decide to stop serving the lower end customers. They derived an optimal timing policy to stop selling to one class in order to serve the more profitable class of customers.

Roundy et al. (2005) worked on the order selection problem from the capacity allocation angle. They considered the case of a manufacturer of automotive parts that produces a wide variety of parts with significant set up times. The manufacturer has to quickly come to a decision whether to accept or reject an order after considering its capacity. They treated the problem as an NP hard problem and noted that three heuristics using genetic algorithms, simulation annealing, and linear programming proved to be promising.

Feng and Xiao (2006) integrated the pricing and capacity allocation decisions in a continuous time model. Maglaras and Meissner (2006) also considered maximizing profit over a time horizon by employing capacity allocation and pricing strategies. They developed heuristics for pricing and capacity controls in a multiple product environment.

Jin and Wu (2006) modeled capacity reservation in the electronics industry where the degree of perishability of products and capacity is highly driven by the innovations occurring in the industry. This produces demand volatility where reservation of capacity can act as a risk sharing mechanism by allowing the customer to reserve a future capacity of the facility at a cost. The paper also presents a discussion of similarities and differences between capacity reservation and other supply chain contracts.

\subsection{Market Segmentation Research}

Structural decisions for demand management involving segmentation and differentiation mechanisms have provided successful tactical means for companies to achieve optimum revenues. Biller et al. (2005) provide an early work in this direction. They investigated the importance of direct to customer business model to improve long term supply chain performance. 
A key research in customer segmentation is reported by Kocabiyikoglu and Popescu (2005). They studied the impact of customer segmentation in a realistic environment where demand is stochastic and price dependent. They showed that a combined strategy of dynamic pricing and protection level for higher-end customers leads to better profits.

Raju et al. (2006) investigated the impact of learning to calculate reorder level in a system where dynamic pricing is practiced. For the system considered, there are two segments of customers. Captive customer class represents loyal customers while the shoppers class reflects customers who are moved into action by promotions and discounts. The seller is the learning agent in the system and uses learning to arrive at optimal prices which will optimize the seller's metric of performance.

A different stream of literature in market segmentation addresses firms that try to achieve optimal inventory policy and production schedule on the basis of segmentation. Duran et al. (2007) considered a two customer class environment and developed a priority differentiation strategy for the different classes of customers and derived optimal threshold values for inventory and production. Benjaafar and Elhafsi (2006) considered the more realistic situation of multiple classes of customers and formulated the problem as a Markovian decision process and derived an optimal policy for production and inventory levels.

Structural decisions in revenue management also involve selecting the form in which selling is carried out. The impact of Internet in commerce and the advent of electronic auction market places cannot be neglected. Caldentey and Vulcano (2007) model a system where the seller faces Poisson arrival of customers in an online auction environment. They studied the structural properties of the decision problem and developed an equilibrium strategy that yields optimum results.

\section{SUMMARY}

Revenue management is an umbrella term for strategies, tactics, and techniques intended to maximize revenue/profit by allocating a company's capacity to different customers at different prices. It is the science and art of determining where each customer is on the service versus price sensitivity continuum and offering them a product that meets their needs, while optimizing profits for the firm (Pinchuk, 2002). Its scope spans service industries, such as airlines, hotels, car rental, and Internet service providers which share the same characteristics (i.e., fixed capacity and a highly uncertain demand), as well as newer areas, such as retail, entertainment, financial services, health care, and manufacturing. The general principles of revenue management are widely applicable; however, each particular application must carefully address the requirements of the specific industry.

Revenue management is a scientific way of dynamically managing prices, inventories, and capacities of perishable services. It deals with modeling and optimization of demand management decisions. It covers the traditional issues of forecasting, inventory control, and dynamic pricing. However, as the research literature surveyed in this paper demonstrates, today revenue management can control and make great improvements on marketing, distribution, and product development techniques and results by considering the effects of competition, learning, and strategic consumer behavior. Indeed, the research landscape presented in this paper paints a vista of future research directions in manufacturing revenue management based on a systematic approach to understanding, anticipating, and capitalizing on the customer's purchasing behavior.

\section{AUTHOR INFORMATION}

S. Hossein Cheraghi is Dean of the School of Engineering at Western New England College in Springfield, MA. Prior to that he was Professor and Chair of the Industrial and Manufacturing Engineering Department at Wichita State University. His primary research and teaching interest is in production systems, geometric error evaluation of produced parts, and analysis of complex systems. During his career he has had over 100 publications in international journals and conferences and has received over $\$ 4.5 \mathrm{M}$ funding from a number of funding agencies. 
Mohammad Dadashzadeh has been affiliated with University of Detroit (1984-1989) and Wichita State University (1989-2003) where he served as the W. Frank Barton Endowed Chair in MIS. Since 2003, he has been serving as Professor of MIS and Director of the Applied Technology in Business (ATiB) Program at Oakland University. Dadashzadeh has authored 4 books and more than 50 articles on information systems and has served as the editor-inchief of Journal of Database Management.

Prakash Venkitachalam is a graduate of Master's Program in Industrial and Manufacturing Engineering at Wichita State University.

\section{REFERENCES}

1. Adida, E., and Perakis, G., "Dynamic Pricing and Inventory Control: Uncertainty and Competition," Operations Research, forthcoming, 2009.

2. Adida, E., and Perakis, G., "A Robust Optimization Approach to Dynamic Pricing and Inventory Control with No Backorders," Mathematical Programming, 107(1), pp. 97-129, 2006.

3. Aggarwal, G., Feder, T., Motawani, R., and Zhul, A., “Algorithms for Multi Product Pricing,” In Automata, Languages and Programming, Springer, New York, 2004.

4. Araman, V., and Caldentey, R., "Dynamic Pricing for Non-Perishable Products with Demand Learning," Operations Research, forthcoming, 2009.

5. Aydin, G., and Porteus, E.L., "Manufacturer-to-Retailer versus Manufacturer-to-Consumer Rebates in a Supply Chain," In Retail Supply Chain Management (Edited by N. Agrawal and S. Smith), Springer, New York, 2005.

6. Benjaafar, S., and Elhafsi, M., "Production and Inventory Control of a Single Product Assemble-to-Order System with Multiple Customer Classes," Management Science, 52(12), pp. 1896-1912, 2006.

7. Biller, S., and Swann, J.L., "Pricing for Environmental Compliance in the Automotive Industry," Interfaces, 36(2), pp. 118-125, 2006.

8. Biller, S., Chan, L.M., Simchi-Levi, D., and Swann, J.L., "Dynamic Pricing and the Direct-to-Customer Model in the Automotive Industry," Electronic Commerce Research, 5(2), pp. 309-334, 2005.

9. Bitran, G., and Caldentey, R., "An Overview of Pricing Models for Revenue Management," Manufacturing \& Service Operations Management, 5, pp. 203-229, 2003.

10. Bitran, G.R., Caldentey, R., and Vial, R., Pricing Policies for Perishable Products with Demand Substitution, Working Paper, New York University, 2006.

11. Caldentey, R., and Wein, L.M., "Revenue Management of a Make-to-Stock Queue," Operations Research, 54, pp. 859-875, 2006.

12. Caldentey, R., Vulcano, G., "Online Auction and Revenue Management," Management Science, 53(5), pp. 795-813, 2007.

13. Carr, S., and Duenyas, I., "Optimal Admission Control, and Sequencing in a Make To Stock/ Make To Order Production System,” Operations Research, 48(5), pp. 709-720, 2000.

14. Carrol, W.J., and Grimes, R.C., "Evolutionary Changes in Product Management: Experiences in the Car Rental Industry," Interfaces, 25(5), pp. 84-104, 1995.

15. Çelik, S., and Maglaras, C., "Dynamic Pricing and Lead-Time Quotation for a Multiclass Make-to-Order Queue," Management Science, 54(6), , pp. 1132-1146, 2008.

16. Charnsirisakskul, K., Griffin, P.M. and Keskinocak, P., "Order Selection and Scheduling with Leadtime Flexibility," IIE Transactions, 36, pp. 697-707, 2004.

17. Cohen, M.A., "Joint Pricing and Ordering Policy for Exponentially Decaying Inventory with Known Demand,", Naval Research Logistics Quarterly, 24(2), pp. 257-268, 1977.

18. Duran, S., Liu, T.M, Simchi-Levi, D., and Swann, J.L., "Optimal Production and Inventory Policies of Priority and Price-Differentiated Customers," IIE Transactions, 39, p. 845-861, 2007.

19. Elmaghraby, W., and Keskinocak, P., "Dynamic Pricing in the Presence of Inventory Considerations: Research Overview, Current Practices, and Future Directions," Management Science, 49, pp. 1287-1309, 2003.

20. Feng, Y., and Xiao, B., "Revenue Management with Two Market Segments and Reserved Capacity for Priority Customers," Advances in Applied Probability, 32(3), pp. 800-823, 2000. 
21. Feng, Y., and Xiao, B., "Integration of Pricing and Capacity Allocation for Perishable Products," European Journal of Operations Research, 168(1), pp. 17-34, 2006.

22. Fleischmann, M., Hall, J.M., and Pyke, D.F., Smart Pricing: Linking Pricing Decisions with Operational Insights, Erasmus Research Institute of Management (ERIM), 2004.

23. Gallego, G., and van Ryzin, G.J., "Optimal Dynamic Pricing of Inventories with Stochastic Demand Over Finite Horizons," Management Science, 40(8), pp. 999-1020, 1993.

24. Gallien, J., Tallec, Y.L., and Schoenmeyr, T., A Model for Make-To-Order Revenue Management, Working Paper, Massachusetts Institute of Technology, 2004.

25. Gayon, J.P., and Dallery, Y., "Dynamic vs Static Pricing in a Make-To-Stock Queue with Partially Controlled Production," OR Spectrum, 29(2), pp. 193-205, 2007.

26. Gayon J.P., Talay, I., Karaesmen, F., and Ormeci, E.L., "Dynamic Pricing and Replenishment in a Production/Inventory System with Markov-Modulated Demand," Probability in the Engineering and Informational Sciences, 23, pp. 205-230, 2009.

27. Geunes, J., Romeijn, H.E., and Taaffe, K., "Requirements Planning with Pricing and Order Selection Flexibility," Operations Research, 54(2), pp. 394-401, 2006.

28. Harris, F.H., and Pinder, J.P., "A Revenue Management Approach to Demand Management and Order Booking in Assemble-To-Order Manufacturing,” Journal of Operations Management, 13(4), pp. 299-309, 1995.

29. Jayaraman, V., and Baker, T., "The Internet As An Enabler for Dynamic Pricing of Goods," IEEE Transactions on Engineering Management, 50(4), pp. 470-477, 2003.

30. Jin, M., and Wu, S.D., Modeling Capacity Reservation in High-Tech Manufacturing, Working Paper, Lehigh University, 2001.

31. Kapuscinski, R., and Tayur, S., Dynamic Capacity Reservation in a Make-To-Order Environment, Working Paper, Carnegie Mellon University, 2000.

32. Kimes, S.E., "Yield Management: A Tool for Capacity Constrained Service Firms," Journal of Operations Management, 8(4), pp. 348-363, 1989.

33. Kocabiyikoglu, A., and Popescu, I., Joint Pricing and Revenue Management with General Stochastic Demand, Working Paper, INSEAD, 2005.

34. Kuhn, H., and Defregger, F., "Revenue Management for a Make-To-Order Company with Limited Inventory Capacity", OR Spectrum, 29(1), pp. 137-156, 2007.

35. Lin, K., "Dynamic Pricing with Real-Time Demand Learning," European Journal of Operational Research, 174, pp. 522-538, 2006.

36. Littlewood, K., "Forecasting and Control of Passenger Bookings," AGIFORS Symposium Proceedings, 12, pp. 95-117, 1972.

37. Maglaras, C., and Zeevi, A., Pricing and Design of Differentiated Services: Approximate Analysis and Structural Insights, Working Paper, Columbia University, 2004.

38. Maglaras, C., and Meissner, J., "Dynamic Pricing Strategies for Multi Product Revenue Management Problem," Manufacturing \& Service Operations Management, 8(2), 2006.

39. Maglaras, C., "Revenue Management for a Multi Class Single-Server Queue via a Fluid Model Analysis", Operations Research, 54(5), 2006.

40. McGill, J.I., and van Ryzin, G.J., "Revenue Management: Research Overview and Prospects," Transportation Science, 33(2), pp. 233-256, 1999.

41. Modarres, M., and Nazemi, J., "Yield Management in Manufacturing: A Conceptual Model \& Research Propositions", Management Knowledge, 70, pp. 143-170, 2005.

42. Montgomery, A.L., The Implementation Challenge of Pricing Decision Support Systems for Retail Managers, Working Paper, Carnegie Mellon University, 2004.

43. Morris, J., A Simulation-based Approach to Dynamic Pricing, Ph.D. Dissertation, Massachusetts Institute of Technology, 2001.

44. Narahari, Y., Raju, C.V.L., Ravikumar, K., and Shah, S., "Dynamic Pricing Models for Electronic Business," Sadhana, 30(2/3), pp. 231-255, 2005.

45. Netessine, S., "Dynamic Pricing of Inventory/Capacity with Infrequent Price Changes," European Journal of Operational Research, 174(1), pp. 553-580, 2006.

46. Pak, K., and Piersma, N., Airline Revenue Management: An Overview of OR Techniques 1982-2001, Econometric Institute Report EI 2002-03, 2002. 
47. Pinchuk, M., "Revenue Management's Ability to Control Marketing, Pricing and Product Development: Part II," Journal of Revenue and Pricing Management, 1(2), pp. 174-182, 2002,

48. Raju, C.V.L., Narahari, Y., and Ravikumar, K., "Learning Dynamic Prices in Electronic Retail Markets with Customer Segmentation," Annals of Operations Research, 143(1), pp 59-75, 2006.

49. Relihan, W., "The Yield Management Approach to Hotel Room Pricing," Cornel Hotel and Restaurant Administration Quarterly, 30(1), pp. 40-45, 1989.

50. Roundy, R., Chen, D., Chen, P., Cakanyildirim, M., Freimer, M.B., and Melkonian, V., "Capacity-Driven Acceptance of Customer Orders for a Multi-Stage Batch Manufacturing System: Models and Algorithms", IIE Transactions, 37(12), pp. 1093-1105, 2005.

51. Shen, Z.J.M., and Su, X., "Customer Behavior Modeling in Revenue Management and Auctions: A Review and New Research Opportunities," Production and Operations Management, 16(6), pp. 713-728, 2007.

52. Swann, J.L., Dynamic Pricing Models to Improve Supply Chain Performance, Ph.D. Dissertation, Northwestern University, 2001.

53. Talluri, K.T., and van Ryzin, G.J., The Theory and Practice of Revenue Management, Springer, New York, 2004.

54. Weatherford, L.R., and Bodily, S.E., “A Taxonomy and Research Overview of Perishable-Asset Revenue Management: Yield Management, Overbooking, and Pricing," Operations Research, 40(5), pp. 831-844, 1992.

55. Xu, X., and Hopp, W.J., Dynamic Pricing and Inventory Control: The value of Demand Learning, Working Paper, Northwestern University, 2005. 